\title{
Land Quality, Sustainable Development and Environmental Degradation in Agricultural Districts: A Computational Approach based on Entropy Indexes
}

Ilaria Zambon ${ }^{1}$, Andrea Colantoni ${ }^{1}$, Margherita Carlucci ${ }^{2}$, Nathan Morrow ${ }^{3}$, Adele Sateriano ${ }^{4}$, Luca Salvati $^{4}$

${ }^{1}$ Department of Agricultural and Forestry scieNcEs (DAFNE), Tuscia University, Via S. Camillo de Lellis, I-01100 Viterbo, Italy

${ }^{2}$ Department of Social and Economic Science, University of Rome La Sapienza, Piazzale A. Moro 5, I-00185 Rome, Italy

${ }^{3}$ Tulane University, Payson Program in International Development at the School of Law, New Orleans, USA

${ }^{4}$ Italian Council for Agricultural Research and Economics (CREA-RPS), Via della Navicella 2-4, I-00184 Rome, Italy

Correspondence to:

Andrea Colantoni, $\mathrm{PhD}$

University of Tuscia

Phone: + 3967005413

Fax: +3967005711

E-mail address: colantoni@unitus.it 


\title{
Land Quality, Sustainable Development and Environmental Degradation in Agricultural Districts: A Computational Approach based on Entropy Indexes
}

\begin{abstract}
Land Degradation (LD) in socio-environmental systems negatively impacts sustainable development paths. This study proposes a framework to LD evaluation based on indicators of diversification in the spatial distribution of sensitive land. We hypothesize that conditions for spatial heterogeneity in a composite index of land sensitivity are more frequently associated to areas prone to LD than spatial homogeneity. Spatial heterogeneity is supposed to be associated with degraded areas that may act as hotspots for future degradation processes. A diachronic analysis (1960-2010) was carried out at the agricultural district scale in Italy to identify environmental factors associated to spatial heterogeneity in the level of land sensitivity to degradation based on the Environmentally Sensitive Area Index (ESAI). In 1960, diversification in the level of land sensitivity measured through two common indexes of entropy (Shannon's diversity and Pielou's evenness) increased significantly with the ESAI, indicating a high level of land sensitivity to degradation. In 2010, surface area classified as 'critical' to LD was the highest in districts with evident diversification in the spatial distribution of ESAI values, confirming the hypothesis formulated above. Entropy indexes, based on observed alignment with the concept of $\mathrm{LD}$, constitute a valuable base to inform mitigation strategies against desertification.
\end{abstract}

Key words: Environmental indicators, Desertification, Sustainable development, Multivariate statistics, Mediterranean basin. 


\section{INTRODUCTION}

Sustainable agriculture has been assumed to play a pivotal role in the conservation of plant and animal biodiversity (e.g. Toy et al., 2002; Weissteiner et al., 2011).Traditional agricultural systems contribute to eco-compatible uses of rural land, preserving soil quality and ensuring long-term ecosystem functioning (Siciliano, 2009). Rural landscapes with high natural value have experienced both land abandonment and crop intensification with land-use changes and loss of traditional practices and cultural heritage preserved by local communities (Navarro and Pereira, 2012; Agnoletti, 2007; Salvati and Zitti, 2007a). Kosmas et al. (2015), Corbelle-Rico et al. (2012), Helming et al. (2011) and Strijker (2005) have identified the main socioeconomic consequences of crop intensification and land abandonment at the local scale, offering original approaches in the analysis of environmental degradation, land management practices and implementation of existing policies (Kosmas et al., 2015; Salvati et al., 2008; EEA, 2005; Recatala et al., 2002; Kosmas et al., 1999; Rubio and Bochet, 1998). Research on adaptive capacity of agricultural districts has significantly improved understanding of complex socioecological systems, clarifying the effectiveness of both formal and informal responses to external shocks (Ibarrarà et al., 2010; McCarthy et al., 2001; Emadodin et al., 2012; Watson et al., 1998).

Biophysical processes have continuously shaped the socio-environmental profile of rural landscapes and local communities (Salvati et al., 2015). Together with climate aridity, land-use changes and increased human pressure, land degradation - a global problem with negative implications for both humans and nature - has recently expanded in both affluent and emerging countries (Hermann and Hutchinson, 2005; Santos and Cabral, 2003; Graaff and Epping, 1999; European Environment Agency, 1998; Lopez-Bermudez, 1997; Perez-Trejo, 1994; Angelakis et al., 1988). Increased competition for land resulted in a decline of soil quality with serious reduction of land productivity, biodiversity and ecosystem services (Zdruli, 2014; Imeson, 2012; Emadodin and Bork, 2011; Emadodin et al., 2009; Zinck et al., 2004). In regions with a long history of human settlement and land-use (Blondel, 2006; Hernández et al., 2015), socioeconomic factors mixed with spatially-variable biophysical conditions influencing socioecological local systems and eliciting complex responses to natural resource degradation (Salvati et al., 2015; Zurlini et al., 2014; Zaccarelli et al., 2008; Kurttila, 2001; Berkes and Folke, 1998). Soil degradation and the increased land sensitivity to desertification are possible results of the combination of biophysical conditions such as arid climate, low vegetation cover, poor soils and water scarcity (Hernández et al., 2015; Ferrara et al., 2014; Salvati et al., 2011; 
Saura et al., 2011a, 2011b; Geri et al., 2010; Lavado Contador et al., 2009; Simeonakis et al., 2007; Bielsa et al., 2005; Feoli et al., 2003; Moonen et al., 2002; Garcia Latorre et al., 2001; Kosmas et al., 2000a; Preiss et al., 1997).

Economically-disadvantaged and marginal rural contexts in dry environmental conditions are typically found in Mediterranean Europe (Salvati and Carlucci, 2011). In these conditions, land degradation has been demonstrated to be particularly intense as a result of land abandonment, soil erosion, rural poverty and loss of land value (Salvati and Zitti, 2009a, 2009b), being intimately related to overgrazing, wildfires, unsustainable exploitation of water and soil resources and environmental pollution, e.g. caused by pesticides and herbicides (Salvati and Carlucci, 2011; Santos and Cabral, 2003; Beaufoy, 2001; Cirio, 1997). Expansion of degraded areas has increasingly involved traditional agricultural systems, determining a progressive depletion of fertile land, loss of biological and economic productivity, soil erosion, habitat fragmentation and reduced ecosystem services (Salvati et al., 2014; Costantini et al., 2009; Salvati et al., 2008; Salvati and Zitti, 2008, 2009a; Montanarella, 2007; Simeonakis et al., 2007; Gisladottir and Stocking, 2005; Brandt et al., 2003; Tanrivermis, 2003).

Depletion of high-quality cropland has been also associated to urban expansion in flat and accessible rural districts (Recatalá et al., 2000). A total of $9000 \mathrm{~km}^{2}$ of rural land have been converted to urban use in the 1990s (EEA and JRC, 2010), growing steadily between 2000 and 2006 (Recatalá and Sacristán, 2014). Population growth in urban areas has in turn stimulated an increased food demand that may lead to crop intensification (Emadodin et al., 2012; Gardi et al., 2014), which often aggravates LD (Bakr et al., 2012; Kangalawe et al., 2010; Adamo and Crews-Meyer, 2006; UNCCD, 2002; Worldwatch Institute, 1998).

Multifaceted relationships between land sensitivity to degradation and basic drivers of landscape transformations have been observed in Mediterranean environments, involving differentiated socioeconomic and biophysical factors (Lal, 2001). An effective assessment of LD requires a comprehensive analysis of the evolution of socio-ecological systems over time and space (Thornes, 2004). Despite extensive research focusing on Mediterranean environments (Bahreini and Pahlavanravi, 2013; Jafari and Bakhshandehmehr, 2013; Abdel Kawy and Belal, 2011; Benabderrahmane and Chenchouni, 2010; Brandt, 2005; Basso et al., 2000; Kosmas et al., 1999, 2000a,b), relatively few studies were aimed at identifying vulnerable areas over large regions (Leman et al., 2016; Salvati et al., 2014; Symeonakis et al., 2014; Lavado Contador et al., 2009), investigating their spatial dynamics over relatively long time periods (Basso et al., 2012). The Mediterranean Desertification and Land Use (MEDALUS) approach identifies Environmentally Sensitive Areas (ESAs) to LD through a 
multi-factor approach incorporating soil, climate, vegetation and land management indicators (Kosmas et al., 1999). The ESA approach is simple, robust and adaptable to new information (Ferrara et al., 2012; Brandt et al., 2003; Kosmas et al., 2003). Using a composite index called the ESAI, the degree of land sensitivity and the effectiveness of policies combating desertification, can be evaluated according to a detailed land evaluation system based on multiple criteria and thresholds (Salvati and Carlucci, 2010).

Agricultural districts, intended as potentially vulnerable socio-ecological contexts to land degradation are suitable spatial units to assess the impact of environmental policies at regional and local scale (Salvati and Zitti, 2008). Salvati and Carlucci (2013) studied the latent relationship between productive and ecological attributes of Italian agricultural districts and land sensitivity to degradation. According to Salvati and Bajocco (2011), the intense growth of sensitive areas to degradation in Italy between 1960 and 2010 is the result of an increased human pressure on agricultural soils, coupled with climate aridity and landscape fragmentation (Salvati and Carlucci, 2013). Land Degradation (LD) determined serious consequences to traditional cropping systems in the Mediterranean rural landscapes (Bajocco et al., 2012). Decreased crop productivity (Salvati and Carlucci, 2013; Salvati, 2010; Ibanez et al., 2008; Conacher and Sala, 1998) or increased poverty in rural populations (Lorent et al., 2008) are typical outcomes of land degradation (Basso et al., 2000). Nonetheless, recent studies demonstrate that $\mathrm{LD}$ can be controlled through adequate land management measures (Bakr et al., 2012).

Based on these premises, this study provides an in-depth investigation of changes in biophysical and socioeconomic conditions of agricultural districts over time with the objective to assess local-scale spatial diversification in the level of land susceptibility to degradation, taken as a proxy of desertification risk. Mediterranean rural areas are characterized by an evident diversity in agricultural systems (Salvati and Bajocco, 2011). Despite all European countries offer typical agricultural productions, the majority high-quality products is found in Mediterranean countries (Jongman, 2002). Socioeconomic transformations determining processes of landscape homogenization or fragmentation, may reflect in a higher level of homogeneity or heterogeneity in the level of land sensitivity to degradation, representing a possible threat to biodiversity resources (Jongman, 2002).

Assumed that southern Europe rural landscapes have experienced both homogenization and fragmentations processes (Jongman, 2002), an in-depth investigation on the changing distribution of the ESA index over time and space by means of the concepts of diversification and heterogeneity may contribute to foresee sensitive contexts to LD. In this sense, Italy 
represents an attractive case given the complex spatial distribution of areas sensitive to degradation, resulting from the joint action of multiple geographical gradients (Salvati and Zitti, 2008; Salvati, 2010). Being classified as a sensitive country to desertification according to United Nation Convention to Combat Drought and Desertification (UNCCD) Annex IV, Italy has experienced intense processes of Land Degradation (LD), especially in the driest areas of southern Italy (Salvati and Zitti, 2008).

The increase over time in the level of vulnerability with spatially heterogeneous land-use structures, affects specific uses of land including mixed urban-rural mosaics (Ferrara et al., 2015; Salvati, 2013). According to Kefi et al. (2007), vegetation patchiness at a very local scale is an early-warning indicator of desertification risk. Being aware that arid ecosystems are among the most sensitive ecosystems to climate change (Schroter et al., 2005), diversity and evenness in land-use structures - reflecting homogeneity (or heterogeneity) in the level of sensitivity to land degradation - were proposed as proxies of desertification risk at the district scale, when considering homogeneous socioeconomic local systems. Based on evidences provided by Kefi et al. (2007) at the spatial scale of land patch, a more heterogeneous distribution of sensitive land in agricultural districts is hypothesized to be associated with higher exposure to land degradation and increasing rates of growth in the level of land sensitivity to degradation, possibly reducing the effectiveness of regional policies against desertification (Salvati and Carlucci, 2011, 2014). Spatial heterogeneity in the ESAI has frequently indicated the occurrence of degraded areas that may act as hotspots for future degradation processes (Bajocco et al., 2015).

Based on these premises, our study assumes the local districts defined by the Italian National Institute of Statistics (1958) and partitioning Italy into homogeneous agricultural areas as the spatial unit of analysis. Agricultural districts are homogeneous socio-environmental systems that identify clusters of municipalities with similar ecological and agronomic characteristics (Recanatesi et al., 2015). Evaluating latent relationships between the average level of land sensitivity to degradation and its spatial heterogeneity at the agricultural district scale provides interesting information for compiling a regional strategy for the mitigation of desertification risk in European Mediterranean countries. Pielou's evenness and Shannon's diversity indexes were used to estimate local-scale diversification in the ESA index at the spatial scale of agricultural districts over the last 50 years (1960-2010) in Italy. The study hypothesizes that a higher level of diversification in the spatial distribution of basic ESAI classes was associated with increased rates of change in the level of land sensitivity over time. Homogeneous 
agricultural districts are supposed to be less exposed to desertification risk, being possibly more resilient to LD (Thornes, 2004).

\section{METHODOLOGY}

\subsection{Study area}

The area considered in this study includes the whole of Italy $\left(301,330 \mathrm{~km}^{2}\right)$. Italian land is characterized by undulated topography (23\% lowlands, $42 \%$ uplands, 35\% mountains) and multifaceted rural landscapes with traditional crop systems shaped by spatially-varying environmental conditions. A total of 773 agricultural districts were considered as elementary spatial units of analysis, excluding some smaller islands (e.g. Ponza, Capri, Giglio, Ischia, Procida, Tremiti). Agricultural districts were delineated by the Italian National Institute of Statistics (Istat, 2006) on the base of biophysical (topography, climate, soil) and socioeconomic variables (prevailing crop system, land value, human settlements).

\subsection{Assessing land sensitivity to degradation}

We considered the notion of 'land sensitivity to degradation' proposed by Kosmas et al. (1999) in the framework of the MEditerranean Desertification And Land USe (MEDALUS) project: 'a state of a local system' depending primarily on (i) quality of natural capital (soil, water, vegetation), (ii) climate regime and (iii) anthropogenic pressures (Kosmas et al., 2000a,b). The MEDALUS project introduced a comprehensive assessment of changes over time in four quality dimensions (climate, soil, vegetation and land management) considered important factors related to LD in the Mediterranean region (e.g. Montanarella, 2007; Sivakumar, 2007; Simeonakis et al., 2007). The procedure adopted refers to the Environmentally Sensitive Area (ESA) approach and includes 14 elementary variables, elaborated through simplified statistical tools and spatial analysis with the purpose of developing a combined index of land sensitivity, called the ESAI. Four elementary variables were respectively considered in the assessment of soil quality (soil depth, texture, parent material, slope) and vegetation quality (protection from soil erosion, wildfire risk, resistance to drought, plant cover); three elementary variables were respectively used to evaluate climate quality (precipitation, aridity, aspect) and land management quality (population density, demographic growth, land-use intensity). 
The ESA framework identifies four quality indicators: Climate Quality Index (CQI); Soil Quality Index (SQI); Vegetation Quality Index (VQI); and land Management Quality Index (MQI). These indicators were calculated as the geometric mean of the sensitivity scores of each elementary variable (Salvati el al., 2016). Quality indicators assume a value ranging between 1 (lowest sensitivity to degradation) and 2 (the highest sensitivity to degradation). The ESAI was computed as the geometric mean of the four quality indicators with neutral weighting, adopting the following land classification: (i) non affected areas or very low sensitive areas to LD (ESAI $<1.3)$; (ii) low sensitivity areas to LD $(1.3<\mathrm{ESAI}<1.4)$; (iii) areas with medium sensitivity to LD $(1.4<$ ESAI < 1.5); and (iv) highly sensitive areas to LD (ESAI > 1.5). The ESAI classification system is aimed at identifying critical areas that need specific mitigation actions against LD (Kosmas et al., 1999).

The ESA approach is one of the most used procedures to classify land according to the degree of sensitivity to degradation (Salvati and Bajocco, 2011; Salvati and Zitti, 2009a,b; Basso et al., 2000). The main advantages of the ESA are (i) flexibility in the use of input variables and (ii) simplicity of land classification system based on the intrinsic level of sensitivity to selected biophysical and socioeconomic conditions (Ferrara et al., 2012). The outcomes of the ESA model have been extensively validated at several sites in Mediterranean Europe (Salvati and Zitti, 2008; Basso et al., 2000; Kosmas et al., 1999). Lavado Contador et al. (2009) demonstrate that the ESAI is a proxy of LD showing significant correlations with a number of indicators of soil degradation. The variables considered in this study were derived from consistent, referenced and updatable data sources (Salvati et al., 2012). However, since LD is a complex phenomenon driven by multiple factors (Hill et al., 2008), some of them could be underestimated in the ESA scheme (Montanarella, 2007). In this sense, Salvati et al. (2012) have demonstrated that using a larger and independent set of LD indicators leads to the identification of a spatial distribution of sensitive land to degradation coherent with the ESAI (Salvati et al., 2012). Multiple correlations between elementary ESA variables and an exhaustive set of LD indicators provided similar results to what was obtained from the application of the standard ESA scheme (Salvati and Zitti, 2009b).

\subsection{Entropy indicators}

Two entropy indicators were used to assess spatial diversification and heterogeneity in the spatial distribution of the ESAI scores at the agricultural district scale in Italy: Shannon's 
diversity $\left(\mathrm{H}^{\prime}\right)$ and Pielou's evenness (J) indexes. The H' index (Shannon and Weaver, 1949) was calculated as:

$$
H^{\prime}=-\Sigma^{n}{ }_{i=1} p_{i} \log p_{i}
$$

where $\mathrm{n}$ is the number of ESAI score classes and $\mathrm{p}_{\mathrm{i}}$ is the proportion of surface area of each $\mathrm{i}-\mathrm{th}$ class. This index estimates the average uncertainty in a finite community, ranging from 0 to highly positive values and evaluating the level of spatial diversification of the ESAI for each agricultural district. By dividing $\mathrm{H}^{\prime}$ by the $\mathrm{H}_{\max }$ value based on the number of ESAI classes in a given district, J index assesses evenness of the ESAI values (Pielou, 1966) in a scale ranging between 0 and 1 , respectively from low to high evenness:

$$
\mathrm{J}=\mathrm{H}^{\prime} / \mathrm{H}_{\max }
$$

where $\mathrm{H}_{\max }$ is the logarithm of the number of classes with surface area $>0$ (Ludwig and Reynolds, 1988). According to Li and Sun (2000), changes in the ESAI H' index may indicate landscape processes of interest for desertification assessment; changes in the $\mathrm{J}$ index may also report the variable distribution of sensitive land to degradation and its potential increase at the landscape scale. Maps of $\mathrm{H}^{\prime}$ and $\mathrm{J}$ indexes were prepared using the ArcGIS software (ESRI Inc., Redwoods, USA).

\subsection{Standard ESA variables}

A total of 14 context indicators based on the ESA scheme (Table 1) were calculated for each study year (1960, 1990, 2000, 2010). Separate figures of averages and coefficients of variation for each quality indicator (CQI, SQI, VQI, MQI) and the ESAI were estimated at each district using the 'zonal statistics' tool provided with ArcGIS software (Salvati and Zitti, 2008). The percent share of land classified as 'fragile' and 'critical' (respectively $1.225<$ ESAI $<1.375$ and ESAI > 1.375) in total landscape and the minimum and maximum ESAI value in each agricultural district were finally calculated.

\subsection{Contextual indicators}

An ancillary set of indicators were considered to assess the basic characteristics of any given district: (i) Sou (classifying districts on the base of the latitude gradient: '0' indicates northern and central Italy districts, '1' indicates southern Italy districts); (ii-iii) two indicators classifying 
districts on the base of elevation: Low (' 0 ' indicates hilly or mountainous districts, ' 1 ' indicates flat districts) and Mou ('0' indicates mountainous districts, '1' indicates flat or hilly districts); (iv) Sea ('0' indicates inland districts, '1' indicates coastal districts); (v) Area (indicating the surface area of each agricultural district, $\mathrm{km}^{2}$ ).

\subsection{Statistical analysis}

The analysis framework evaluated changes in the spatial relationship between entropy indicators $\left(\mathrm{H}^{\prime}, \mathrm{J}\right)$ in the spatial distribution of the ESAI (section 2.3), standard ESA variables (section 2.4) and contextual indicators (section 2.5). Pair-wise correlations between each of the selected ESAI variables and each entropy indicator were assessed using Spearman nonparametric analysis testing for significant coefficients at $p<0.05$ after Bonferroni's correction for multiple comparisons. A Principal Component Analysis (PCA) was run on the dataset including entropy indicators and standard ESA variables separately for two time points (1960 and 2010) with the aim at evaluating (i) the contribution of each ESA variable in the overall level of land sensitivity to degradation in each agricultural district and (ii) latent, multiple relationships between diversification in the ESAI spatial distribution and the level of land sensitivity to degradation. Variables with loading $>|0.5|$ were considered significantly associated to a given component. The Kaiser Meyer-Olkin measure of sampling adequacy and Bartlett's test of sphericity were used to evaluate reliability of the factor model, verifying respectively (i) if partial correlations between variables are small and (ii) if the correlation matrix is an identity matrix (Salvati and Zitti, 2009a). Hierarchical clustering was finally carried out separately for 1960 and 2010 on the same dataset submitted to PCA, with the aim of classifying agricultural districts into homogeneous groups by applying a computation strategy based on Euclidean distances and Ward's amalgamation rule. Clustering determined which indicators have contributed to the definition of relevant spatial groups characterized by specific environmental conditions and level of diversification in the spatial distribution of the ESAI.

\section{RESULTS}

\subsection{Evaluating the spatial structure of the ESAI in Italy}


Results of this study outline the main changes in basic environmental conditions predisposing land to degradation at the spatial scale of agricultural districts in Italy. In 1960, ESAs were primarily situated in Southern Italy, except for few districts including some metropolitan regions in central and northern Italy (Figure 3). A huge increase in the average ESAI score between 1960 and 2010 was observed in the above mentioned areas and, more generally, along the Adriatic sea coast and the Po valley. A descriptive analysis of Shannon's diversity $\left(\mathrm{H}^{\prime}\right)$ and Pielou's evenness ( $\mathbf{J}$ ) indexes applied to the spatial distribution of ESAI scores at the scale of agricultural districts provided similar results. The spatial distribution of $\mathrm{H}^{\prime}$ index values outlines that southern Italy and Apennine districts display the most heterogeneous environmental conditions shaping land sensitivity to degradation. An increasing level of diversification in the ESAI was observed throughout Italy, in contrast with the dominant spatial pattern found in lowland areas, such as the Po valley. These areas support high-input agricultural systems characterized by crop intensification and homogeneous environmental conditions (low values of $\mathrm{H}^{\prime}$ and $\mathrm{J}$ indexes) leading to medium-high ESAI scores. A mediumhigh value of $\mathrm{J}$ index was attributed to the majority of rural districts in upland and mountainous regions, being characterized by a diversified landscape with crop mosaic, agro-forest land and traditional communities.

Results of a non-parametric Spearman rank correlation analysis corroborate this preliminary findings (Table 2). The $\mathbf{J}$ index varied significantly along the latitude gradient $(1990,2000)$ being higher in northern districts than elsewhere in Italy. At the beginning of the study period, Both $\mathrm{H}^{\prime}$ and $\mathrm{J}$ indexes increased with elevation, VQI, average ESAI score and the percent area of 'fragile' land in total landscape. Fifty years later, $\mathrm{H}$ ' and $\mathrm{J}$ correlated positively with coefficients of variation of both VQI and ESAI. The SQI coefficient of variation was stably and positively correlated with $\mathrm{H}^{\prime}$ index for both 1960 and 2010. In most recent decades, spatial heterogeneity in the ESAI score increased with percent area of 'critical' land and the maximum ESAI score observed in each district.

\subsection{Profiling agricultural districts based on entropy indexes}

Figure 3 illustrates the most relevant change over time in the selected entropy indicators assessing spatial diversification of the ESAI scores at the rural district scale. In 1960, most agricultural districts with medium-high $\mathrm{H}^{\prime}$ index were located in Southern Italy and in western side of central Italy. During 1960-2010, the H' index increased homogeneously throughout the country and a similar pattern was observed for the spatial distribution of $\mathbf{J}$ index, with the 
highest rates of change being recorded in Sardinia and Sicily. In this sense, the spatial distribution of both $\mathrm{H}^{\prime}$ and $\mathrm{J}$ indexes followed a latitude gradient with the lowest values of both indexes concentrated in the Po valley. Spearman analysis (Table 3) indicated that diversification in the spatial distribution of the ESAI was the highest in districts experiencing a rapid increase in the ESAI score in the earlier decades of this study (1960-1990, 1990-2000). The reverse pattern was observed in the last decade, with negative changes in the level of land sensitivity to degradation being observed in districts with high diversification and evenness in the spatial distribution of the ESAI score.

\subsection{Identifying latent factors influencing the spatial distribution of the ESAI}

A Principal Component Analysis (PCA) was run to summarize the environmental variables profiling agricultural districts and to point out the latent relationship with $\mathrm{H}^{\prime}$ and $\mathrm{J}$ indexes in the spatial distribution of the ESAI. PCA removed the partial correlation between variables incorporating significant information in a limited number of independent components derived as a linear combination of the most relevant variables. Referring to 1960 , component 1 was negatively associated with H', ESAI, CQI, VQI, FRAG, CRIT, MIN, and MAX. The two entropy indicators ( $\mathrm{H}^{\prime}$ and J), ESAICV and VQICV received significant loadings to component 2. Moderate changes in the structure of both components 1 and 2 were observed for 2010. VQI and MQI received negative loadings to component $1 ; \mathrm{H}^{\prime}$ and ESAICV received positive loadings. Component 2 had positive loadings for the two entropy indicators and the ESAICV. The changing structure of components 1 and 2 for $\mathrm{H}^{\prime}$ and $\mathrm{J}$ indexes outlines the increasing complexity of basic environmental conditions in the Italian agricultural districts along the study period.

\subsection{Determining coherent spatial patterns in the ESA variables}

A hierarchical clustering (Figure 2) identified similarities in the spatial distribution of the elementary variables contributing to determine a high or low level of land sensitivity to degradation. Two homogeneous groups were identified: the first group is composed by two sub-clusters including respectively four variables (the two entropy indicators, ESAICV, VQICV) and three variables (CQICV, SQI, SQICV). Cluster membership was relatively stable over time. The second group was again composed by two sub-clusters: ESAI, FRAG, CQI and 
MQI clustered together and were clearly separated from CQI, MIN, MAX and CRIT forming a second sub-cluster.

\section{DISCUSSION}

Multiple feedbacks associated with a spatially-heterogeneous distribution of sensitive land to degradation, require dedicated assessment techniques and place-specific mitigation measures. Analysis has to consider the specific characteristics of territorial contexts and local communities, possibly identifying distinct trends in the levels of land sensitivity due to the action of diversified environmental drivers and socioeconomic factors of change. Transformation of rural landscapes in Italy reflects a progressive increase of land sensitivity to degradation (Salvati et al., 2016). Such changes have been influenced by multifaceted drivers, emphasizing the intimate relationship between human activities and land resources (Khanji, 2016; MEA 2005a,b; Gleick et al., 2002; UNEP, 1994; WCED-CMED, 1987). According to Hermann and Hutchinson (2005), relevant causes of LD are associated to the spatial-temporal dynamics of four dimensions (climate, vegetation, soil, socioeconomic processes), shaping impacts of land management strategies at local scale (Salvati, 2014; Herrmann and Hutchinson, 2005).

Our study proposed the notion of 'spatial diversification' in the level of land sensitivity to degradation in Italian rural districts, with the objective to defining potential hotspots for desertification risk (Recanatesi et al., 2015). Empirical findings indicate that the level of land sensitivity to degradation is influenced by spatial heterogeneity in the environmental conditions at the base of LD. Agricultural districts with spatially-homogeneous environmental conditions were more exposed to $\mathrm{LD}$ in recent decades in respect to the time period immediately following the World War II. Diversification in the spatial distribution of the ESAI has been associated with specific territorial contexts characterized by a high degree of land sensitivity. Cropland demonstrated to be particularly prone to environmental conditions leading to LD when the spatial structure of agro-forest districts (e.g. crop mosaic, landscape fragmentation, traditional forestry systems, agricultural practices and typical productions, rural communities) has been compromised. Human-driven LD has been observed in both economically-marginal rural areas of southern Italy and affluent districts of northern Italy with soil and climate conditions getting worse in the last decades (Salvati and Carlucci, 2013). According to Salvati et al. (2015), Mediterranean rural areas are considered as increasingly exposed to desertification risk, due to joint action of climate aridity and socioeconomic pressures (see also 
Salvati and Zitti, 2009b; Lorent et al., 2008; Mendelsohn and Dinar, 2003; Olesen and Bindi, 2002). Despite Southern Italy is widely recognized as a risky area (Salvati and Bajocco, 2011), LD sensitivity was advancing rapidly also in central and even northern Italy. Following Salvati and Carlucci (2013), the spatial distribution of rural districts sensitive to LD was fragmented and heterogeneous.

In this sense, since the early 1950s, urbanization has been the main responsible for the conversion of rural land to urban uses, causing various impacts on ecosystem structure, function and dynamics such as loss of rural areas, soil degradation and landscape fragmentation (Salvati and Zitti, 2007b, 2009a; Salvati et al., 2007; Weng, 2007; Tanrivermis, 2003; Luck and Wu, 2002; Garcia Latorre et al., 2001; Pickett et al., 2001; Antrop and Van Eetvelde, 2000; McDonnell et al., 1997). Landscape fragmentation was a key factor determining increased land sensitivity to degradation (Salvati and Zitti, 2009a). Fragmented landscapes are characterized by weak connections between natural elements causing a deterioration of their ecological functions and negative impacts on biodiversity (Cook, 2002; Hidding and Teunissen, 2002; Jongman, 2002; Serrano et al., 2002; Wilcox and Murphy, 1985). As land fragmentation is commonly observed in agricultural systems on both regional, local, and farm level (Hidding and Teunissen, 2002), natural habitats and traditional crop systems require a sustainable management aimed at reducing patchiness and ecological isolation. Land fragmentation and farm marginalization determine a progressive erosion of the agricultural base, causing less effective farm support operations and facilities, which raise operating costs (Pfeffer and Lapping, 1995; Lapping, 1979).

With rapidly adjusting crop systems to the globally increasing demand of food, landscapes transformations in the Mediterranean basin reflect contrasting processes involving rural districts, spanning from crop intensification to farmland abandonment. Especially crop intensification has frequently led to homogeneous rural landscapes with low natural, agronomic and cultural diversity, possibly associated to a high (and spatially homogeneous) level of land sensitivity to degradation.

Preserving the spatial structure of high-quality farmland and crop mosaics is therefore a reasonable strategy with the aim to reduce negative environmental impacts of farming. In this sense, the ESAI allows identifying which areas require specific actions mitigating or reversing LD (Glenn et al., 1998; Herrmann and Hutchinson, 2005). According to our results, soil and vegetation are the components mostly associated to spatially-heterogeneous conditions predisposing land to high sensitivity to degradation. Imbalanced environmental conditions in terms of natural capital require measures minimizing soil degradation and protecting natural 
vegetation with the final objective to improve components' balance and spatial heterogeneity in LD (Hamdouch and Zuindeau, 2010). Together with soil and vegetation, climate quality is considered a component strongly associated to imbalanced ecological conditions possibly leading to LD (Montanarella, 2007; Sivakumar, 2007; Feoli et al., 2003) in the Mediterranean region (Lavado Contador et al., 2009; Salvati and Zitti, 2009b). Local climate regimes are only indirectly influenced by environmental policies, suggesting to implement strategies for the mitigation of LD (Herrmann and Hutchinson, 2005).

As stated by UNCCD, addressing land degradation and desertification in the Mediterranean Basin includes: (i) policy reforms and enforcement; and (ii) adequate research on sustainable land-use and the restoration of already degraded lands. In order to implement the UNCCD and the Italian National Action Programme (NAP), regional authorities have to provide specific intervention plans, identifying the most sensitive areas to desertification. Policies should incorporate measures reducing impacts of rapid biophysical and socioeconomic transformations particularly in marginal districts with low population density, limited accessibility and a traditionally rural organization (Esposito et al., 2016; Tan, 2006). As a consequence, the present work confirms the pivotal role played by a comprehensive analysis of different components of natural as possible targets for integrated environmental policies against desertification (Salvati and Zitti, 2008). In this ambit, diversification in the spatial distribution of an index of land sensitivity to degradation can be considered an early-warning indicator of desertification risk.

While being spatially-heterogeneous, the increase in the level of sensitivity over the last 50 years requires mitigation actions specifically designed for sensitive districts with high $\mathrm{H}^{\prime}$ and $\mathrm{J}$ index and a medium-high ESAI score. Land sensitivity to degradation is frequently interpreted as a combination of "risk exposure and stress, and difficulty coping with them" (Chambers, 1989), the possible loss (Cutter et al., 2003), the capacity to predict, manage, defend against and recover the impact of a natural risk (Blaikie et al., 1994) and the ability to be harmed (Rayner and Malone, 2001). Foreseeable scenarios should not be limited to the risks associated with climate change and biophysical conditions, being possibly extended to the issue of socioeconomic sensitivity (Rayner and Malone, 2001).

Adaptive approaches based on local-scale information provide a comprehensive framework for policy implementation and mitigation of negative externalities over different temporal contexts (Cushman and McKelvey, 2010; Vernier et al., 2009; Walters, 1986). For example, incentives and subsidies supporting specific farm types or farm-holder groups, individual crop or food products have often determined a spatially-diversified increase in land sensitivity with impact 
on desertification risk (Juntti and Wilson, 2004). The European Union soil thematic strategy, taken as a relevant policy combating desertification, has identified threats to soil functions (e.g. erosion, salinization, compaction, sealing and contamination) and suggested regional-wide and place-specific practical actions to mitigate the negative impact of soil degradation (Montanarella, 2007). At the same time, EU subsidies for marginal rural areas sustained agricultural systems with low profits, producing a negative impact on soil quality while preserving biodiversity and traditional agronomic practices (Onate and Peco, 2005). In this ambit, the results of our study contribute to the development of specific land policies for homogeneous and heterogeneous agricultural districts, informing effective mitigation strategies against desertification.

Our approach constitutes a reliable monitoring system that combines information on the longterm sustainability of rural districts based on a composite index of sensitivity to LD (Feoli et al., 2003). Soil degradation patterns and desertification risk can be effectively monitored using a mixed qualitative and quantitative approach in order to describe the evolutionary path of each district (Salvati et al., 2015). According to Bakr et al. (2012), desertification processes should be monitored over time to define more effective sustainable development measures. A high degree of land sensitivity indicates candidate targets for adopting mitigation measures against desertification (Gisladottir and Stocking, 2005). Early-warning indicators of desertification based on diversification in the spatial distribution of the ESAI are particularly helpful to design strategies specifically adapted to local contexts and place-specific environmental dynamics of change.

\section{REFERENCES}

Adamo, S.B., Crews-Meyer, K.A., 2006. Aridity and desertification: exploring environmental hazards in Jáchal, Argentina. Appl. Geogr. 26, 61-85.

Agnoletti, M., 2007. The degradation of traditional landscape in a mountain area of Tuscany during the 19th and 20th centuries: Implications for biodiversity and sustainable management. Forest Ecology and Management 249, 5-17.

Antrop, M., Van Eetvelde, V., 2000. Holistic aspects of suburban landscapes: visual image interpretation and landscape metrics. Landscape Urban Plan 50(1-3), 43-58.

Bahreini, F., Pahlavanravi, A., 2013. Assess and mapping the environmental sensitivity to desertification (A case study in Boushehr Province, Southwest Iran). Int. J.Agric. Crop Sci. 5(18), 2172-2183. 
Bajocco, S., De Angelis, A., Perini, L., Ferrara, A., Salvati, L., 2012. The Impact of Land Use/Land Cover Changes on Land Degradation Dynamics: A Mediterranean Case Study. Environmental Management 49 (5), 980-989.

Bakr, N., Weindorf, D.C., Bahnassy, M.H., El-Badawi, M.M., 2012. Multi-temporal assessment of land sensitivity to desertification in a Fragile Agro-ecosystem. Environmental indicators. Ecol. Indic. 15, 271-280.

Basso, F., Bove, E., Dumontet, S., Ferrara, A., Pisante, M., Quaranta, G., Taberner, M., 2000. Evaluating environmental sensitivity at the basin scale through the use of geographic information systems and remotely sensed data: an example covering the Agri basin-Southern Italy. Catena 40, 19-35.

Basso, B., De Simone, L., Cammarano, D., Martin, E.C., Margiotta, S., Grace, P.R., Yeh, M.L., Chou, T.Y., 2012. Evaluating responses to land degradation mitigation measures in Southern Italy. Int. J. Environ. Res. 6(2), 367-380.

Bajocco S., Salvati L., Smiraglia D., Ceccarelli T., Perini L. 2015. Planning for sustainable agro-forest systems: protected areas and soil degradation hotspots in Italy. Soil Science and Plant Nutrition 61, 404-413.

Benabderrahmane, M.C., Chenchouni, H., 2010. Assessing environmental sensitivity areas to desertification in eastern Algeria using Mediterranean desertification and land use MEDALUS model. Int. J. Sustain. Water Environ. Syst. 1(1), 5-10.

Berkes, F., Folke, C. (Eds.), 1998. Linking Social and Ecological Systems: Management Practices and Social Mechanisms for Building Resilience. Cambridge University Press, Cambridge.

Bielsa, I., Pons, X., Bunce, B., 2005. Agricultural abandonment in the North Eastern Iberian peninsula: the use of basic landscape metrics to support planning. J. Environ. Plan. Manag. 48, 85-102.

Blondel, J., 2006. The 'Design' of Mediterranean Landscapes: A Millennial Story of Humans and Ecological Systems during the Historic Period. Human Ecology 34(5), 713-729.

Brabec, E., Smith C., 2002. Agricultural land fragmentation: the spatial effects of three land protection strategies in the eastern United States. Landscape and Urban Planning 58, 255-268.

Brandt, J., Geeson, N., Imeson, A., 2003. A desertification indicator system for Mediterranean Europe. DESERTLINKS Project, Bruxelles (www.kcl.ac.uk/desertlinks).

Brandt, J., 2005. Desertification information system to support National Action Programmes in the Mediterranean (DISMED). DIS4ME, Desertification Indicator System for Mediterranean Europe (www.unibas.it/desertnet/dis4me/using_dis4me/dismed.htm accessed November 2012). 
Ceccarelli T., Salvati L., Bajocco S., Perini L. 2014. Investigating syndromes of agricultural land degradation through past trajectories and future scenarios. Soil Science and Plant Nutrition 60(1), 60-70.

Chambers, R., 1989. Sensitivity, coping and policy, Institute for Development Studies (IDS). Bulletin 20, 1-7.

Conacher, A.J., Sala, M., 1998. Land Degradation in Mediterranean Environments of the World. Wiley, Chichester.

Cook, E.A., 2002. Landscape structure indices for assessing urban ecological networks Landscape and Urban Planning 58, 269-280.

Corbelle-Rico, E., Crecente-Maseda, R., Sante-Riveira, I., 2012. Multi-scale assessment and spatial modelling of agricultural land abandonment in a European peripheral region: Galicia (Spain). Land Use Policy 29(3), 493-501.

Costantini, E.A.C., Urbano, F., Aramini, G., Barbetti, R., Bellino, F., Bocci, M., Bonati, G., Fais, A., L'Abate, G., Loj, G., Magini, S., Napoli, S., Nino, P., Paolanti, M., Perciabosco, M., Mascone, F., 2009. Rationale and methods for compiling an atlas of desertification in Italy. Land Degrad. Dev. 20, 261-276.

Cushman, S.A., McKelvey, K.S., 2010. Data on distribution and abundance: monitoring for research and management. In: Cushman, S.A., Huettman, F. (Eds.), Spatial Complexity, Informatics and Wildlife Conservation. Springer Tokyo, Tokyo, 111-130.

Cutter, S., Boruff, B., Shirley, W. L., 2003. Social sensitivity to environmental hazards. Social Science Quarterly 84(2), 242-261.

European Environment Agency (EEA), 2005. EEA core set of indicators guide. Technical report No. 1. European Environment Agency, Copenhagen.

European Environment Agency (EEA), 2010. The European environment - state and outlook 2010: land use. European Environment Agency, Copenhagen.

Emadodin, I., Bork, H. R., 2011. Degradation of soils as a result of long-term human-induced transformation of the environment in Iran: an overview. Journal of Land Use Science. doi:10.1080/1747423X.2011.560292.

Emadodin, I., Narita D., Bork, H.R., 2012. Soil degradation and agricultural sustainability: an overview from Iran. Environ Dev Sustain 14, 611-625.

Emadodin, I., Reiss, S., Bork, H.R., 2009. A study of the relationship between land management and soil aggregate stability: A case study near Albersdorf, Northern-Germany. Journal of Agriculture and Biological Sciences 4, 48-53. 
Esposito, P., Patriarca, F., Perini, L., Salvati, L., 2016. Land degradation, economic growth and structural change: evidences from Italy. Environ Dev Sustain 18, 431-448.

Feoli, E., Giacomich, P., Mignozzi, K., Oztürk, M., Scimone, M., 2003. Monitoring desertification risk with an index integrating climatic and remotely-sensed data: an example from the coastal area of Turkey. Management of the Environmental Quality 14, 10-21.

Ferrara, C., Moretti, V., Serra, P., Salvati, L., 2015. Towards a sustainable agro-forest landscape? Assessing land degradation (1950-2010) and soil quality in Castelporziano forest and peri-urban Rome, Italy. Rendiconti Lincei 26(3), 597-604. DOI: 10.1007/s12210-0140354-5.

Ferrara, A., Salvati, L., Sateriano, A., Nolè, A. 2012. Performance Evaluation and Costs Assessment of a Key Indicator System to Monitor Desertification Sensitivity. Ecological Indicators 23, 123-129.

Ferrara, C., Salvati, L., Tombolini, I., 2014. An integrated evaluation of soil resource depletion from diachronic settlement maps and soil cartography. Geoderma 232-234, 394-405.

Fry, G., Gustavsson, R., 1996. Testing landscape design principles: the landscape laboratory. In: Jongman, R.H.G. (Ed.) Ecological and landscape consequences of land use change in Europe. European Centre for Nature Conservation ECNC, Tilburg, 143-154. ECNC Publication Series on Man and Nature 2.

Garcia Latorre, J., Garcia-Latorre, J., Sanchez-Picon, A., 2001. Dealing with aridity: socioeconomic structures and environmental changes in an arid Mediterranean region. Land Use Policy 18, 53-64.

Geri, F., Amici, V., Rocchini, D., 2010. Human activity impact on the heterogeneity of a Mediterranean landscape. Appl. Geogr. 30, 370-379.

Gisladottir, G., Stocking, M., 2005. Land degradation control and its global environmental benefits, Land Degradation and Development 16, 99-112.

Glenn, E., Stafford Smith, M., Squires, V., 1998. On our failure to control desertification: implications for global change issues, and research agenda for the future. Environmental Science and Policy 1, 71-78.

Goodland, R., Daly, H., 1996. Environmental sustainability: universal and non-negotiable. Ecological Applications 6(4), 1002-1017.

Graaff, J., Epping, L.A.A.J., 1999. Olive oil production and soil conservation in southern Spain in relation to EU subsidy policies. Land Use Policy 16, 259-267. 
Hamdouch, A., Zuindeau, B., 2010. Sustainable development, 20 years on: methodological innovations, practices and open issues. Journal of Environmental Planning and Management 53(4), 427-438.

Helming, K., Diehl, T., Kuhlman, T., Jansson, P.H., Verburg, M., Bakker, M., Perez-Soba, L., Jones, P., Johannes Verkerk, P., Tabbush, J., Breton Morris, Z., Drillet, J., Farrington, P., LeMouël, P., Zagame, T., Stuczynski, G., Siebielec, H.,Wiggering, A., 2011. Ex ante impact assessment of policies affecting land use, Part B: application of the analytical framework. Ecol. Soc. $16(1), 29-38$.

Helbron, H., Schmidt, M., Glasson, J., Downes, N., 2011. Indicators for strategic environmental assessment in regional land use planning to assess conflicts with adaptation to global climate change. Ecological Indicators 11, 90-95.

Hermann, S.M., Hutchinson, C.F., 2005. The changing contexts of the desertification debate. Journal of Arid Environment 63, 538-555.

Hernández, A., Miranda, M., Arellano, E.C., Saura, S., Ovalle, C., 2015. Landscape dynamics and their effect on the functional connectivity of a Mediterranean landscape in Chile. Ecological Indicators 48, 198-206.

Hidding, M.C., Teunissen, A.T.J., 2002. Beyond fragmentation: new concepts for urban-rural development. Landscape and Urban Planning 58, 297-308.

Hill, J., Stellmes, M., Udelhoven, T., Röder, A., Sommer, S., 2008. Mediterranean desertification and land degradation. Mapping related land use change syndromes based on satellite observations. Global and Planetary Change 64, 146-157.

Ibanez, J., Martinez Valderrama, J., Puigdefabregas, J., 2008. Assessing desertification risk using system stability condition analysis. Ecological Modelling 213, 180-190.

Ibarraràn, M.E., Malone, E.L., Brenkert, A.L., 2010. Climate change sensitivity and resilience: current status and trends for Mexico. Environ Dev Sustain 12, 365-388.

Imeson, A., 2012. Desertification, Land Degradation and Sustainability. Wiley, Chichester. ISTAT, 2006. Atlante statistico dei comuni. Istituto Nazionale di Statistica, Roma.

Jafari, R., Bakhshandehmehr, L., 2013. Quantitative mapping and assessment of environmentally sensitive areas to desertification in Central Iran. Land Degrad. Dev., http://dx.doi.org/10.1002/ldr.2227.

Jongman, R.H.G, 2002. Homogenisation and fragmentation of the European landscape: ecological consequences and solutions. Landscape and Urban Planning 38, 211-221.

Jongman, R.H.G, 2005. The New Dimensions of the European Landscapes. Springer Science \& Business Media. 
Juntti, M., Wilson, G.A., 2004. Conceptualising desertification in southern Europe: stakeholders interpretations and multiple policy agendas. Eur. Environ. 15, 228-249.

Kangalawe, R.Y.M., Lyimo, J.G., 2010. Population dynamics, rural livelihoods and environmental degradation: some experiences from Tanzania. Environ Dev Sustain 12, 985997. DOI 10.1007/s10668-010-9235-y.

Kéfi, S., Rietkerk, M., Alados, C. L., Pueyo, Y., Papanastasis, V. P., ElAich, A., de Ruiter, P.C., 2007. Spatial vegetation patterns and imminent desertification in Mediterranean arid ecosystems. Nature 449, 213-217.

Khanji, S.E., 2016. An exploration of the interaction between socio-economic productivity and water withdrawal. Environ Dev Sustain. DOI 10.1007/s10668-016-9757-z.

Kosmas, C., Kirkby, M., Geeson, N., 1999. Manual on key indicators of desertification and mapping environmental sensitive areas to desertification. European Commission, Directorate General, Project ENV4 CT 95 0119, EUR 18882, Bruxelles (http://www.kcl.ac.uk/projects/desertlinks/downloads/publicdownloads/ESA\%20Manual.pdf visited in October 2009).

Kosmas, C., Danalatos, N.G., Gerontidis, S., 2000a. The effect of land parameters on vegetation performance and degree of erosion under Mediterranean conditions. Catena 40, 317.

Kosmas, C., Gerontidis, S., Marathianou, M., 2000b. The effect of land use change on soil and vegetation over various lithological formations on Lesvos. Catena 40, 51-68.

Kosmas, C., Kairis, O., Karavitis, C., Acikalin, S., Alcalá, M,. Alfama, P., Atlhopheng, J., Barrera, J., Belgacem, A., Solé-Benet, A., Brito, J., Chaker, M., Chanda, R., Darkoh, M. Ermolaeva, O., Fassouli, V., Fernandez, F., Gokceoglu, C., Gonzalez, D., Gungor, H., Hessel, R., Khatteli, H., Khitrov, N., Kounalaki, A., Laouina, A., Magole, L., Medina, L., Mendoza, M., Mulale, K., Ocakoglu, F., Ouessar, M., Ovalle, C., Perez, C., Perkins, J., Pozo, A., Prat, C., Ramos, A., Ramos, J., Riquelme, J., Ritsema, C., Romanenkov, V., Sebego, R., Sghaier, M., Silva, N., Sizemskaya, M., Sonmez, H., Taamallah, H., Tezcanj, L., de Vente, J., Zagal, E., Zeiliguer, A., Salvati L., 2015. An exploratory analysis of land abandonment drivers in areas prone to desertification. Catena 128, 252-261.

Kurttila, M., 2001. The spatial structure of forests in the optimization calculations of forest planning. Forest Ecol. Manag. 142, 129-142.

Lal, R., 1991. Soil structure and sustainability. Journal of Sustainable Agriculture 1, 67-92.

Lal, R., 2001. Soil degradation by erosion. Land Degrad. Dev. 12, 519-539. 
Lapping, M., 1979. Underpinnings for an agricultural land reformation strategy. J. Soil Water Conserv. 34(3), 124-126.

Lavado Contador, J.F., Schnabel, S., Gomez Gutierrez, A., Pulido Fernandez, M., 2009. Mapping sensitivity to land degradation in Extremadura, SW Spain. Land Degradation and Development 20(2), 129-144.

Leman, N., Ramli, M.F., Khirotdin, R.P.K., 2016. GIS-based integrated evaluation of environmentally sensitive areas (ESAs) for land use planning in Langkawi, Malaysia. Ecological Indicators 61, 293-308.

Li, F., Sun, S., 2000. Applied research of landscape ecology in desertification monitoring and assessment. Journal of Environmental Science 12 (3), 349-354.

Lorent, H., Evangelou, C., Stellmes, M., Hill, J., Papanastasis, V., Tsiourlis, G., Roeder, A., Lambin, E.F., 2008. Land degradation and economic conditions of agricultural households in a marginal region of northern Greece. Global and Planetary Change 64, 198-209.

Luck, M., Wu, J., 2002. A gradient analysis of urban landscape pattern: a case study from the Phoenix metropolitan region, Arizona, USA. Landscape Ecol. 17(4), 327-339.

Ludwig, J.A., Reynolds, J.F, 1988. Statistical ecology: a primer of methods and computing. Wiley Press, New York, New York.

Malkina-Pykh, I.G., Pykh, Y.A., 2008. Quality-of-life indicators at different scales: theoretical background. Ecological Indicators 8(6), 854-862.

McDonnell, M.J., Pickett, S.T.A., Groffman, P., Bohlen, P., Pouyat, R.V., Zipperer, W.C., Parmelee, R.W., Carreiro, M.M., Medley, K.Y., 1997. Ecosystem processes along an urban-torural gradient. Urban Ecosyst. 1, 21-36.

Mendelsohn, R., Dinar A., 2003. Climate, water, and agriculture. Land Economics 79(3), 32841.

Millennium Ecosystem Assessment (MEA), 2005a. Ecosystems and human well-being: synthesis. World Resources Institute. Island Press, Washington, DC.

Millennium Ecosystem Assessment (MEA), 2005b. Ecosystems and human well-being: desertification synthesis. World Resources Institute, Washington, DC.

Montanarella, L., 2007. Trends in land degradation in Europe. In: Sivakumar, M.V., N'diangui, N. (Eds), Climate and land degradation. Springer, Berlin.

Moonen, A.C., Ercoli, L., Mariotti, M., Masoni, A., 2002. Climate change in Italy indicated by agrometeorological indices over 122 years. Agricultural and Forest Meteorology 111, 13-27.

Myers, G., Macnaghten, P., 1998. Rhetorics of environmental sustainability: commonplaces and places. Environment and Planning A 30, 333-354. 
Navarro, L.M., Pereira, H.M., 2012. Rewilding Abandoned Landscapes in Europe. Ecosystems 15(6), 900-912.

Nourry, M., 2008. Measuring sustainable development: some empirical evidence for France from eight alternative indicators. Ecological Economics 67(3), 441-456.

Olesen, J.E., Bindi, M., 2002. Consequences of climate change for European agricultural productivity, land use and policy. Eur. J. Agron. 16(4), 239-262.

Onate, J.J., Peco, B., 2005. Policy impact on desertification: stakeholders' perceptions in southeast Spain. Land Use Policy 22, 103-114.

Pfeffer, M.J., Lapping, M.B., 1995. Prospects for a sustainable agriculture in the northeast's rural/urban fringe. Res. Rural Sociol. Dev. 6, 67-93.

Pickett, S.T.A., Cadenasso, M.L., Grove, J.M., Nilon, C.H., Pouyat, R.V., Zipperer, W.C., Costanza, R., 2001. Urban ecological systems: linking terrestrial ecological, physical, and socioeconomic components of metropolitan areas. Annu. Rev. Ecol. Syst. 32, 127-157.

Pielou, E.C., 1966. Species diversity and pattern diversity in the study of ecological succession. J. Theo. Biol. 10, 370-383.

Preiss, E., Martin, J.L., Debussche, M., 1997. Rural depopulation and recent landscape changes in a Mediterranean region: consequences to the breeding avifauna. Landsc. Ecol. 12, 51-61.

Rayner, S., Malone, E., 2001. Climate change, poverty, and intragenerational equity: The national level. International Journal of Global Environmental Issues 1(2), 175-202.

Recanatesi, F., Clemente, M., Grigoriadis, E., Ranalli, F., Zitti, M., Salvati, L., 2015. A FiftyYear Sustainability Assessment of Italian Agro-Forest Districts. Sustainability 8(1), 32; doi:10.3390/su8010032.

Recatalá, L., Ive, J.R., Baird, I.A., Hamilton, N., Sánchez, J., 2000. Land-use planning in the Valencian Mediterranean Region: using LUPIS to generate issue relevant plans. J. Environ. Manage. 59, 169-184.

Recatalá, L., Sacristán D., 2014. A minimum indicator set for assessing resources quality and environmental impacts at planning level in a representative area of the European Mediterranean Region. Ecological Indicators 45, 160-170.

Rubio, J.L., Bochet, E., 1998. Desertification indicators as diagnosis criteria for desertification risk assessment in Europe. J. Arid Environ. 39, 113-120.

Salvati, L., 2010. Exploring the relationship between agricultural productivity and land degradation in a dry region of southern Italy. New Medit IX(1), 35-40.

Salvati, L., 2013. Monitoring high-quality soil consumption driven by urban pressure in a growing city (Rome, Italy). Cities 31, 349-356. 
Salvati, L., 2014. Toward a 'Sustainable' land degradation? Sensitivity degree and component balance in a rapidly changing environment. Environment, Development and Sustainability 16(1), 239-254.

Salvati, L., Bajocco, S., 2011. Land sensitivity to desertification across Italy: past, present, and future. Applied Geography 31(1), 223-231.

Salvati, L., Carlucci, M., 2010. Estimating land degradation risk for agriculture in Italy using an indirect approach. Ecological Economics 69, 511-518.

Salvati, L., Carlucci, M., 2011. The economic and environmental performances of rural districts in Italy: Are competitiveness and sustainability compatible targets?. Ecological Economics 70, 2446-2453.

Salvati, L., Carlucci, M., 2013. The impact of Mediterranean land degradation on agricultural income: A short-term scenario. Land Use Policy 32, 302-308.

Salvati, L., Carlucci, M., 2014. Zero Net Land Degradation in Italy: The role of socioeconomic and agro-forest factors. Journal of Environmental Management 145, 299-306.

Salvati, L., Carlucci, M., 2015. Towards sustainability in agro-forest systems? Grazing intensity, soil degradation and the socioeconomic profile of rural communities in Italy. Ecological Economics, 112, 1-13.

Salvati, L., Karamesouti, M., Kosmas, K., 2014. Soil degradation in environmentally sensitive areas driven by urbanization: an example from Southeast Europe. Soil Use Manag. 30, 382393.

Salvati, L., Mavrakis, A., Colantoni, A., Mancino, G., Ferrara, A., 2015. Complex Adaptive Systems, soil degradation and land sensitivity to desertification: A multivariate assessment of Italian agro-forest landscape. Science of the Total Environment 521-522, 235-245.

Salvati, L., Perini, L., Ceccarelli, T., Zitti, M., Bajocco, S., 2011. Towards a process-based evaluation of land sensitivity to degradation: a spatio-temporal approach in Italy. Ecological Indicators 11(5), 1216-1227.

Salvati, L., Zitti, M., 2005. Land degradation in the Mediterranean basin: linking bio-physical and economic factors into an ecological perspective. Biota 5, 67-77.

Salvati, L., Zitti, M., 2007a. Territorial disparities, natural resource distribution, and land degradation: a case study in southern Europe. GeoJournal 70, 185-194. DOI 10.1007/s10708008-9124-1.

Salvati, L., Zitti, M., 2007b. Long term demographic dynamics along an urban-rural gradient: implications for land degradation. Biota 8, 61-69. 
Salvati, L., Zitti, M., 2008. Regional convergence of environmental variables: empirical evidences from land degradation. Ecological Economics 68, 162-168.

Salvati, L., Zitti, M., 2009a. The Environmental "Risky" Region: Identifying Land Degradation Processes Through Integration of Socio-Economic and Ecological Indicators in a Multivariate Regionalization Model. Environmental Management 44, 888-898. DOI 10.1007/s00267-0099378-5

Salvati, L., Zitti, M., 2009b. Assessing the impact of ecological and economic factors on land degradation sensitivity through multiway analysis. Ecological Indicators 9, 357-363.

Salvati, L., Zitti, M., Ceccarelli, T., 2008. Integrating economic and ecological indicators in the assessment of desertification risk: suggestions from a case study. Appl. Environ. Ecol. Res. 6, 129-138.

Santos, M., Cabral, J.A., 2003. Development of a stochastic dynamic model for ecological indicators' prediction in changed Mediterranean agroecosystems of north-eastern Portugal. Ecological Indicators 3, 285-303.

Saura, S., Estreguil, C., Mouton, C., Rodríguez-Freire, M., 2011. Network analysis to assess landscape connectivity trends: application to European forests (1990-2000). Ecol. Indic. 11, 407-416.

Scheffer, M., Carpenter, S., Foley, J.A., Folke, C., Walker, B., 2001. Catastrophic shifts in ecosystems. Nature 413, 591-596.

Serrano, M., Sanza, L., Puiga, J., Pons, J., 2002. Landscape fragmentation caused by the transport network in Navarra (Spain) Two-scale analysis and landscape integration assessment. Landscape and Urban Planning 58, 113-123.

Shannon, C.F., Wiener, W., 1949. The Mathematical Theory of Communication. University of Illnois Press, Urbana, USA.

Schroter, D.; Cramer, W.; Leemans, R.; Prentice, I. C.; Araujo, M. B.; Arnell, N. W.; Bondeau, A.; Bugmann, H.; Carter, T. R.; Gracia, C. A.; de la Vega-Leinert, A. C.; Erhard, M.; Ewert, F.; Glendining, M.; House, J. I.; Kankaanpaa, S.; Klein, R. J. T.; Lavorel, S.; Lindner, M.; Metzger, M. J.; Meyer, J.; Mitchell, T. D.; Reginster, I.; Rounsevell, M.; Sabate, S.; Sitch, S.; Smith, B.; Smith, J.; Smith, P.; Sykes, M. T.; Thonicke, K.; Thuiller, W.; Tuck, G.; Zaehle, S.; Zierl, B., 2005. Ecosystem service supply and vulnerability to global change in Europe. Science 310(5752), 1333-1337. DOI: 10.1126/science.1115233.

Serra, P., Pons, X., Saurì, D., 2008. Land-cover and land-use change in a Mediterranean landscape: A spatial analysis of driving forces integrating biophysical and human factors. Applied Geography 28, 189-209. 
Siche, J.R., Agostinho, F., Ortega, E., Romeiro, A., 2008. Sustainability of nations by indices: comparative study between environmental sustainability index, ecological footprint and the energy performance indices. Ecological Economics 66(4), 628-637.

Siciliano, G., 2009. Social multicriteria evaluation of farming practices in the presence of soil degradation. A case study in Southern Tuscany, Italy. Environ. Dev. Sustain. 11, 1107-1133.

Simeonakis, E., Calvo-Cases, A., Arnau-Rosalen, E., 2007. Land use change and land degradation in southeastern Mediterranean Spain. Environmental Management 40, 80-94.

Sivakumar, M.V.K., 2007. Interactions between climate and desertification. Agricultural and Forest Meteorology 142, 143-155.

Strijker, D., 2005. Marginal lands in Europe — causes of decline. Basic Appl. Ecol. 6, 99-106. Symeonakis, E., Karathanasis, N., Koukoulas, S., Panagopoulos, G., 2014. Monitoring sensitivity to land degradation and desertification with the environmentally sensitive area index: the case of Levlos Island. Land Degrad. Dev., http://dx.doi.org/10.1002/ldr.2285.

Tan, X., 2006. Environment, governance and GDP: Discovering their connections. International Journal of Sustainable Development 9, 311-335.

Tanrivermis, H., 2003. Agricultural land use change and sustainable use of land resources in the Mediterranean region of Turkey. J. Arid Environ. 54, 553-564.

Thornes, J.B., 2004. Stability and instability in the management of Mediterranean desertification. In: Wainwright, J., Mulligan, M. (Eds.), Environmental modelling: finding simplicity in complexity. Wiley, Chichester, UK, 303-315.

UNEP, 1994. United Nations Convention to combat desertification in those countries experiencing serious drought and/or desertification, particularly Africa. UNEP, Geneva.

Wang, Y., Ding, Q., Zhuang, D., 2015. An eco-city evaluation method based on spatial analysis technology: A case study of Jiangsu Province, China. Ecological Indicators 58, 37-46.

Weissteiner, C.J., Strobl, P., Sommer, S., 2011. Assessment of status and trends of olive farming intensity in EU-Mediterranean countries using remote sensing time series and land cover data. Ecological Indicators 11, 601-610.

Weng, Y.-C., 2007. Spatiotemporal changes of landscape pattern in response to urbanization. Landscape and Urban Planning 81, 341-353.

Wilcox, B.A., Murphy, D.D., 1985. Conservation Strategy: the effects of fragmentation on extinction. The American Naturalist 125, 879-887.

Zaccarelli, N., Petrosillo, I., Zurlini, G., Riitters, K.H., 2008. Source/sink patterns of disturbance and cross-scale effects in a anarchy of social-ecological landscapes. Ecol. Soc. 13 (1), 26 http://www.ecologyandsociety.org/vol13/iss1/art26/. 
Zdruli, P., 2014. Land resources of the Mediterranean: status, pressures, trends and impacts on future regional development. Land Degrad. Dev. 25(4), 373-384.

Zinck, J. A., Berroteran, J. L., Farshad, A., Moameni, A., Wokabi, S., Van Ranst, E., 2004. Approaches to assessing sustainable agriculture. Journal of Sustainable Agriculture 23, 87-109. Zurlini, G., Jones, K. B., Riitters, K. H., Li B., Petrosillo, I., 2014. Early warning signals of regime shifts from cross-scale connectivity of land-cover patterns. Ecological Indicators 45, 549-560. 
Table 1. Variables considered in this study and the related measurement scale by agricultural district in Italy.

\begin{tabular}{lll}
\hline Acronym & Variable name & Measurement scale \\
\hline $\mathrm{H}$ & Shannon's diversity index & Score ranging from 0 to $\infty$ \\
$\mathrm{J}$ & Pielou's evenness index & Score ranging from 0 to 1 \\
ESAI & Environmentally Sensitive Area Index & Score ranging from 1 to 2 \\
ESAICV & Coefficient of variation in the ESAI score & Percentage \\
CQI & Average Climate Quality Index & Score ranging from 1 to 2 \\
CQICV & Coefficient of variation in the CQI score & Percentage \\
SQI & Average Soil Quality Index & Score ranging from 1 to 2 \\
SQICV & Coefficient of variation in the SQI score & Percentage \\
VQI & Average Vegetation Quality Index & Score ranging from 1 to 2 \\
VQICV & Coefficient of variation in the VQI score & Percentage \\
MQI & Average land Management Quality Index & Score ranging from 1 to 2 \\
MQICV & Coefficient of variation in the MQI score & Percentage \\
FRAG & Surface land classified as 'fragile' $(1.225<$ ESAI < 1.375) & Percentage in total landscape \\
CRIT & Surface land classified as 'critical' (ESAI $>1.375)$ & Percentage in total landscape \\
MIN & Minimum value of the ESAI & Score ranging from 1 to 2 \\
MAX & Maximum value of the ESAI & Score ranging from 1 to 2 \\
\hline
\end{tabular}


Table 2. Pair-wise Spearman rank correlation coefficients between selected environmental variables for each homogeneous agricultural district in Italy and two indicators of entropy in the spatial distribution of the ESAI (H': Shannon's diversity index, J: Pielou's evenness index). Only significant coefficients tested at $p<0.05(\mathrm{n}=762)$ after Bonferroni's correction for multiple comparisons were shown).

\begin{tabular}{lcccccccc}
\hline \multirow{2}{*}{ Variable } & \multicolumn{3}{c}{ Shannon H' diversity index } & \multicolumn{5}{c}{ Pielou J evenness index } \\
\cline { 2 - 8 } & 1960 & 1990 & 2000 & 2010 & 1960 & 1990 & 2000 & 2010 \\
\hline ESAI & 0.45 & & & & & & & \\
ESAICV & 0.85 & 0.91 & 0.92 & 0.92 & 0.58 & 0.69 & 0.69 & 0.75 \\
SQICV & 0.32 & 0.36 & 0.34 & 0.33 & & & & \\
VQI & 0.55 & & & & 0.37 & & & \\
VQICV & 0.65 & 0.74 & 0.75 & 0.75 & 0.47 & 0.59 & 0.60 & 0.65 \\
FRAG & 0.60 & & & & 0.39 & & & \\
CRIT & 0.39 & 0.30 & 0.32 & & & & & \\
MAX & 0.55 & 0.36 & 0.37 & & & 0.30 & 0.34 & \\
Sou & & & & & & -0.30 & -0.31 & -0.38 \\
Low & & -0.44 & -0.44 & -0.45 & & &
\end{tabular}


Table 3. Pair-wise Spearman rank correlation coefficients between $\mathrm{H}^{\prime}$ or $\mathrm{J}$ indexes at the beginning of each time interval and percent annual rate of growth in the ESAI at each time interval and agricultural district (significant coefficients tested at $* 0.001<p<0.05$ or $* * p<$ $0.001(\mathrm{n}=762)$ after Bonferroni's correction for multiple comparisons).

\begin{tabular}{lccc}
\hline Variable & $1960-1990$ & $1990-2000$ & $2000-2010$ \\
\hline $\mathrm{H}^{\prime}$ & $0.14^{* * *}$ & $0.13^{* *}$ & $-0.26^{* * *}$ \\
$\mathrm{~J}$ & $-0.04^{\mathrm{ns}}$ & $0.11^{*}$ & $-0.22^{* *}$ \\
\hline
\end{tabular}


Table 4. Results of a Principal Component Analysis (PCA) applied to variables assessing basic environmental characteristics of the Italian agricultural districts in 1960 (left) and 2010 (right). Variable's loadings $>10.5 \mid$ were shown. The lower panel represents the component score plot (circle identifies the agricultural districts more exposed to LD and with the highest diversification in the ESAI in 2010).

\begin{tabular}{lcccc}
\hline \multirow{2}{*}{ Variable } & \multicolumn{2}{c}{1960} & \multicolumn{2}{c}{2010} \\
\cline { 2 - 5 } & Component 1 & Component 2 & Component 1 & Component 2 \\
\hline Shannon's diversity & -0.65 & 0.65 & 0.58 & -0.72 \\
Pielou's evenness & & 0.54 & & -0.67 \\
ESAI & -0.92 & & -0.89 & \\
ESAICV & & 0.79 & 0.64 & -0.65 \\
CQI & -0.69 & & & -0.55 \\
VQI & -0.78 & & -0.79 & \\
VQICV & & 0.70 & 0.76 & \\
MQI & & & -0.69 & \\
FRAG & -0.87 & & -0.86 & \\
CRIT & -0.65 & & -0.56 & -0.54 \\
MIN & -0.70 & -0.55 & -0.83 & \\
MAX & -0.90 & & -0.57 & -0.73 \\
Expl. Var \% & 38.3 & 19.4 & 38.6 & 22.6 \\
\hline
\end{tabular}

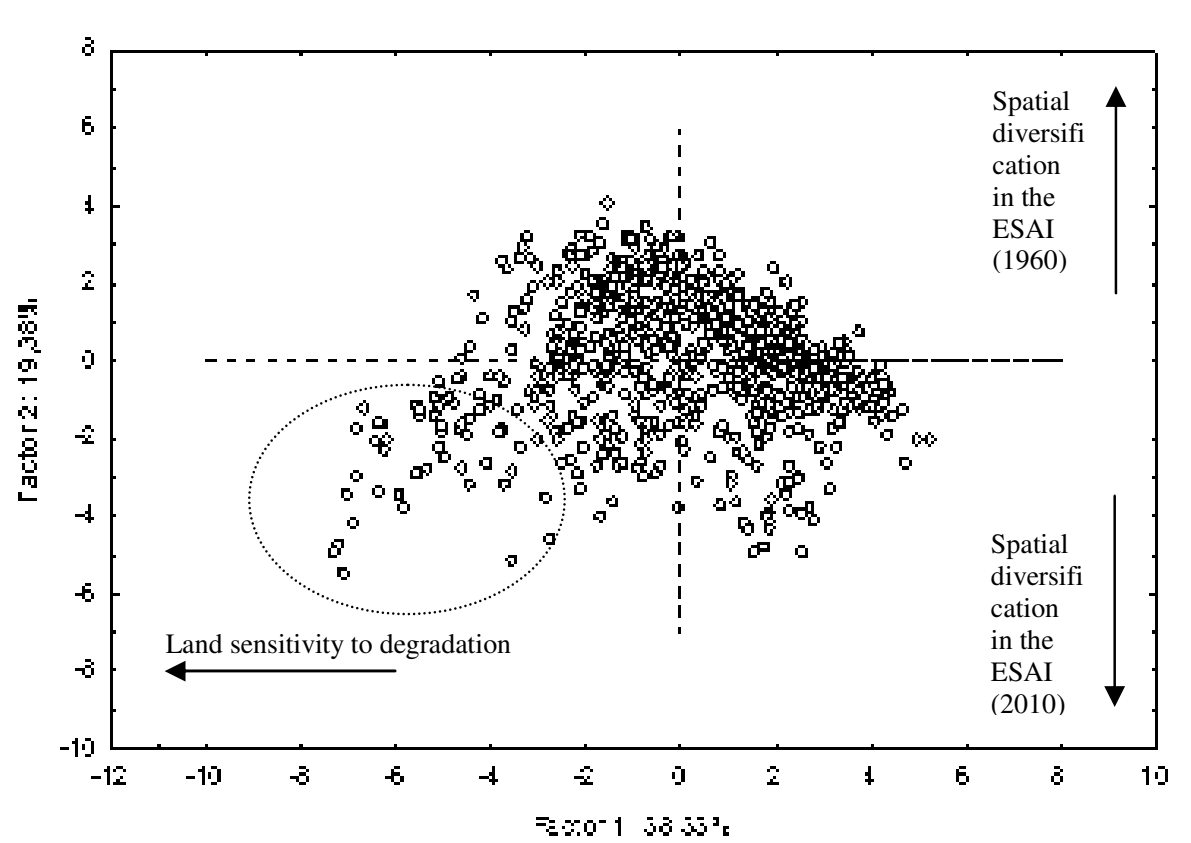


Figure 1. Spatial distribution of the average ESAI score (left), Shannon's Diversity Index (H, middle) and Pielou's Evenness Index (J, right) by year and agricultural district.

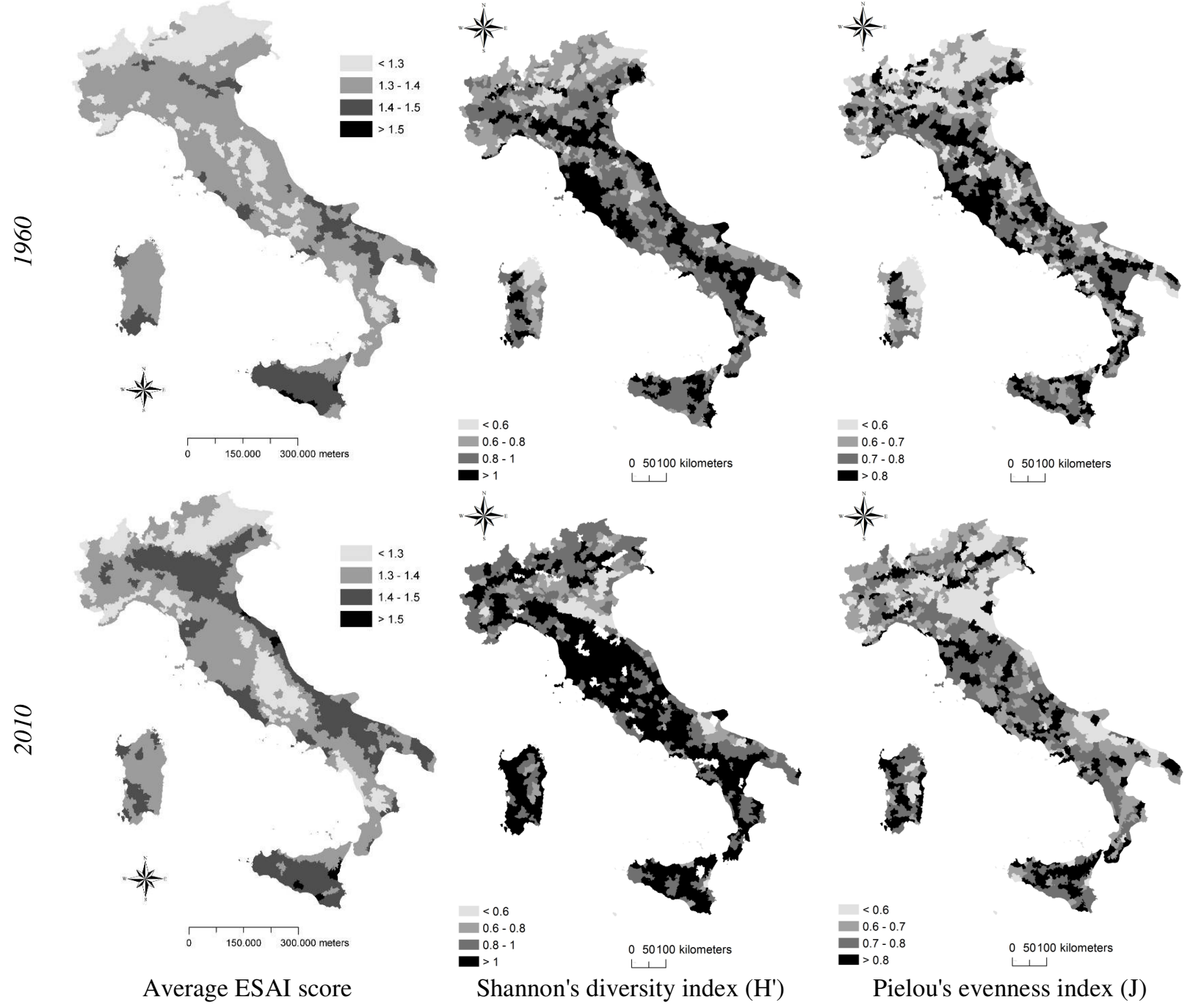


Figure 2. Hierarchical Clustering of the selected variables profiling the Italian agricultural districts by year.
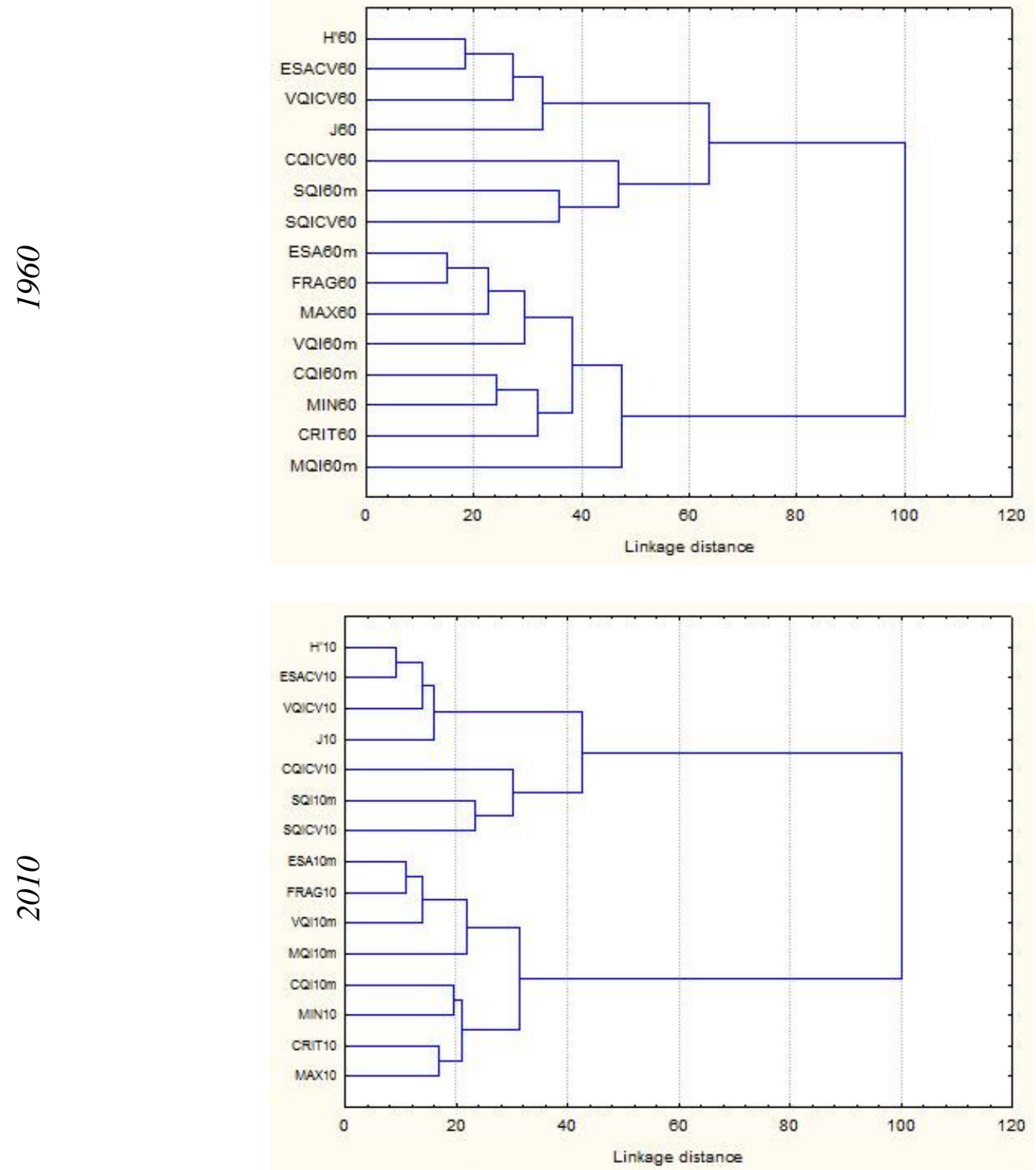